\title{
Sustaining Political and Financial Allocation as a Sustainable Approach in Transport Policy Development: The Case of Indonesia's Railway during the Restructuring Process
}

\author{
Imam Muthohar (Corresponding author) \\ Graduate School of Engineering, Kyushu University, Fukuoka, Japan \\ 744, Motooka, Nishi-ku, Fukuoka, Japan, 819-0395 \\ Tel: 81-92-802-3403Ｅ-mail: muthohar@civil.doc.kyushu-u.ac.jp \\ Tomonori Sumi \\ Graduate School of Engineering, Kyushu University, Fukuoka, Japan \\ 744, Motooka, Nishi-ku, Fukuoka, Japan, 819-0395 \\ Tel: 81-92-802-3403Ｅ-mail: sumi@doc.kyushu-u.ac.jp
}

\begin{abstract}
This paper explores the introduction of transport policy instrumentation, namely the schemes of Public Service Obligation (PSO), Infrastructure Maintenance and Operation (IMO), and Track Access Charges (TAC) as a fundamental way of restructuring the Indonesian national railway system to clarify the relationships between government obligation and the commercial function of train operators. The first five-year implementation of the policies is analyzed to determine the convergence of their objectives and their achievements. Results show that current outcomes are not meeting the objectives because the policies have not been properly implemented. Specifically, funding allocation provided by the government was insufficient; the net payment system affects both present service performance and preparations for future development. In conclusion, sustained political action as a sustainable approach for allocating sufficient funds to the railway sector plays a critical role in improving the subsequent restructuring process of the Indonesian Railways system.
\end{abstract}

Keywords: Policy instrument, Net payment, Sustainable approach

\section{Introduction}

The development of transport policy can encourage the achievement of multiple economic, social, and environmental objectives (UNESCAP-AITD, 2000). However, the issues of how to relate transportation issues with the principle of sustainable development and how policy makers can best make informed decisions are still actively debated (Akinyemi \& Zuidgeest, 2000; Vieira et al, 2007; Banister, 2008; Eriksson et al, 2008; Hatzopoulou \& Miller, 2009). Moreover, in developing countries, because of inadequate financial, human, and knowledge resources, it is difficult to meet such objectives when actually implementing transport policy (Balassa, 1990; Ikhsan, 2007; Saadatian et al, 2010).

Meanwhile, for two decades beginning in the late 1970s, the railway industries of many countries were subject to great pressure in two main respects: 1) the dynamic effects of strong competition, in particular from air and road transport; and 2) critical government finances due to a high level of public subsidies. Therefore, beginning with originally state-owned railways, a restructuring process was begun to overcome this situation (Guislain, 1997; Campos \& Cantos, 2000). The rise of restructuring in the 1990s brought change toward a new concept of transport policy development to be more attractive, competitive, and closer to customers' needs, while also leading to a wider range of market competition in railway industries. Each railway system is unique in its policy development choices because of its characteristics related to goal formulation, geographic size, topography, traffic productivity, and type of market served. Generally, this process has required from 5 to 12 years to complete (Kopicki \& Thompson, 1995; Guislain, 1997; Wu \& Nash, 1998; Campos \& Cantos, 2000; Link, 2004; Crozet, 2004; Mizutani \& Shoji, 2004; Everett, 2006).

A similar circumstance occurred in Indonesia because the main motivation for railway deregulation is to provide better quality of service and encourage competitiveness in balance with role accountability between the public service function of government obligation and the commercial function of train operation. This is symbolized by the enactment of a series of regulations: Government Regulation No. 19/1998 concerning the transformation of PT Kereta Api (PT KA-Indonesian Railway Co., Ltd.); a Joint Decree of Three Ministers in 1999 concerning the Public Service Obligation (PSO), Infrastructure Maintenance and Operation (IMO), and Track Access Charge (TAC) schemes; and Law No. 23/2007 concerning railway provisions which opened up opportunities to new potential entities for involvement in railway industries. Moreover, the national air transport and national telecommunication sectors are examples of success stories following deregulation which enabled the national railways sector to accelerate the restructuring process.

This paper explores the national railway system by first describing the current rail transport policy in Section 2 . Then, Section 3 analyzes the convergence of the various scheme objectives and their achievements. Furthermore, 
Section 4 suggests feasible solutions for these problems as important steps for commencing future development. Finally, the paper is concluded in Section 5.

\section{Overview of current rail transport policy}

\subsection{PSO, IMO, and TAC schemes}

The main motivation behind the development of the PSO, IMO, and TAC schemes was to clarify the relationship between the public service function of government obligation and the commercial function of train operation on the basis of accountability. The World Bank, as an international supervisor of the Railway Efficiency project, supported this policy instrumentation as a fundamental way to restructure the national railway financial system (Ministry of Transport, 1999; State Secretary Minister, 1999).

As stated in the Joint Decree of Three Ministers, i.e., No. KM 19/1999, No. S3/KMK.03/1999, and No. KEP.024/K/03/1999, the schemes are defined as follows:

"PSO is governmental subsidy for economy class passengers through the compensation paid by the government to the operator due to the service provided for economy class passengers, in which the tariff is set by the government. It is calculated by the difference between the operating cost of transporting an economy class train passenger and the revenue from an economy class train passenger tariff. IMO is the government compensation paid to the operator for the cost of infrastructure maintenance and operation. It is calculated by the total cost of the maintenance of tracks, bridges, signals, and electricity, and the cost of railway infrastructure operation. TAC is the operator expenses paid to the government for the use of the railroad infrastructure. It is calculated based on the IMO added to infrastructure depreciation (d) multiplied by intermodal or inter-services balancing policy factors (f)."

Figure 1 illustrates the relationship between the government and the current train operator, PT KA, in the scheme implementation as a model railway budget mechanism. In this formal mechanism, PT KA first proposes a budget for the PSO, IMO, and TAC schemes for one year in the next implementation. The government then organizes interdepartmental meetings among the Ministry of Transport, Ministry of Finance, State Ministry of National Development Planning, and PT KA to discuss the proposed budget and its calculation. Then, once the members reach an agreement, the government prepares an official contract for the PT KA for implementing the schemes for one year. The operator receives payment after it submits a progress report every three months during the implementation. Additionally, three documents are prepared: i) a document describing each scheme's proposal, ii) a document describing the items determined by each scheme, and c) a document describing the realization of the schemes. The funding amount for each scheme for the period of implementation spanning 2000-2004 is shown in Table 1.

\subsection{The restructuring process}

Under Law No. 23/2007, the government should be able to restructure existing railway industries during the three-year period designated for opening up opportunities for further development of railway industries. Some international best practices, combined with the concepts underlying the PSO, IMO, and TAC schemes, have been used as a benchmark for deciding the most appropriate conditions suitable for Indonesia. For example, when an alternative model was proposed and simulated for managing the railway industry on Java Island, Indonesia's most populous region, it achieved good results owing to its combination of vertical unbundling and horizontal unbundling with concessions (Muthohar \& Sutomo, 2003). Vertical unbundling was proposed to separate service operation functions from infrastructure management functions, while horizontal unbundling was proposed as an infrastructure maintenance function based on the region's geographic characteristics, which allowed the region to maintain its status as an existing DAOP (operational area). In line with the above explanation, another study by Lubis and Nurullah (2007) suggested a model at the national level which went beyond both horizontal and vertical restructuring and was based on the regional characteristics of the five main islands of Indonesia. Moreover, the setup of railway institutions could be vertically separated or integrated depending on the geographical conditions in the region, market size, and also the rail business function in the regional economic development agenda put forth by the government.

\section{Comparative analysis of the objectives and achievements: Do they converge? \\ 3.1 Promoting accountability based on efficiency}

Shortly before the abovementioned schemes were issued, there was a dramatic change in the national railway management system, indicated by the transformation of the state-owned enterprise Perusahaan Umum Kereta Api (PERUMKA) to PT KA. The schemes confirmed the role of accountability for the government as the infrastructure owner, and PT KA as the sole service provider, that is, each scheme was independent of each other and had its own separate funding mechanism. Furthermore, it was also made policy that any financing in the PSO, IMO, and TAC schemes would be based on efficiency principles for improving current performance.

In actuality, however, the schemes have not been properly implemented. Muthohar et al. (2009) investigated the use of a net payment system for the PSO, IMO, and TAC schemes instead of independent systems. In this system, payment was calculated by adding the PSO and IMO amounts, and then subtracting the TAC amount. The main 
reason for the development of this system was because there were state budget constraints causing insufficient funds for PSO and IMO payments. In the state budget structure, the Ministry of Finance allocated PSO funds not only for the railway sector, but also for other infrastructure sectors, such as postal service, sea and air transport, and electricity for low income households. The impact of these actions was not only the absence of the total amount required by the three scheme budget allocations, but also ambiguous accountability and the loss of efficiency with respect to the flow of finances, indicated in part by the fact that there was no real cash flow separately applied in each scheme.

\subsection{Providing subsidized transport services for reflecting the equity principle}

The government has an obligation to provide transport to accommodate the mobility of every citizen. Therefore, the principle of equity, including the provision of transport services to all income levels in society, should be implemented in any kind of policy instrumentation. The PSO scheme reflected the provision of subsidized services for those citizens who could not afford them, that is, it represented the distribution of real income in society. By setting a tariff lower than its operational cost, the government paid the difference as compensation to PT KA based on clear criteria, measurable standards, and efficient finances.

As a mix of various general services, including commercial (executive and business class) and freight services, the economy class passenger service covers various types of services, such as long and middle distance intercity services, and urban and suburban local train services. The role of these services is of great importance with respect to supporting mobility, especially during peak commuting and travel periods. Despite this positive achievement, however, service quality problems still remain. For example, priority was given to commercial services, which resulted in lower quality economy class passenger services. With respect to access rights, when economical services are mixed with commercial services, their operational performance is always lessened because vehicles must stop at every crossing or slow down and stop when being passed in single lane traffic. Combined with a lower operational speed, the total travel time and the probability of delays increase. As a result, these conditions cause economy class services to be viewed in an unfavorable light, and thus most people become reluctant to choose them as their preferred modes of transport. Meanwhile, Muthohar et al. (2009) outlined the dispute regarding the divergence between budget plan contracts and their realization after implementation, due to different calculation methods and the lack of allocated funds for PSO payments. Finally, improper PSO implementation affects the performance of economy class trains, resulting in public service quality complaints, which indicate a high level of dissatisfaction.

\subsection{Covering all cost components for track maintenance and operation}

As owner of the infrastructure, the government has a responsibility to finance the maintenance and operation of the railway infrastructure. Considering limited human resources, however, the government has delegated these functions to PT KA based on criteria and standards which place priority on efficiency and safety. This agreement is written in the annual IMO scheme contract.

The available data show that the required funds to meet the stated objectives are not fully realized because of the limited budget allocations driving the enforcement of the net payment system. As a result, improper IMO implementation affects the backlog condition, defined as an accumulation due to a maintenance shortage, resulting in the deterioration of track infrastructures and suboptimal operation, such as reduced or limited running speeds and increased effects of horizontal and vertical vibration, thus causing discomfort and increased risk of derailment. In the case of derailment, the damage to track components is a much larger factor compared with rolling stock and human factors. Yearly derailment rates and lower track running speeds due to speed reductions or other limitations are presented in Tables 2 and 3, respectively.

\subsection{Introducing an infrastructure access charge to encourage competition}

The introduction of a track access charge as a part of the restructuring process is based on the goal of establishing a relationship between the infrastructure owner and the train service operator based on rational and measurable criteria for achieving greater efficiency of rail infrastructure use. It is important to encourage competition in the current new era of rail market competition. The initial basic approach of infrastructure charging, as defined in previous section, used a pricing method that incorporated depreciation and a balancing policy factor.

After examining the outcomes achieved, it is important to note two essential points. First, similar to previous schemes, there is no real cash flow in the TAC scheme from PT KA to the government because of the systemic effects of net payment. Second, the calculation method causes difficulty in some aspects of its implementation. There is a long-standing debate on how to determine the appropriate value of the $f$ factor because there is still no standardized formula for calculating such values. Its yearly variations also increase the complexity of the issue, and as a result, improper TAC implementation affects the ease with which infrastructure charging can be implement. This, in turn, influences the potential for new operators to participate in current new national rail market. However, we also must note the Joint Decree includes the possibility to review and evaluate the method used to charge access to reflect the most efficient use of rail infrastructure. 


\subsection{Analysis results}

We have explored four objectives of the PSO, IMO, and TAC scheme policies. The schemes are critical in that they are issued as policy foundational measures for restructuring the national railway financial system and for preparing for future railway services. After analyzing their combined achievements during the first five years of implementation, we would like to point out that most of the outcomes have not met the original objectives, and that this is mostly due to the use of the net payment system. The impacts of these diverging outcomes, as part of the overall problem, are shown in Figure 2 in a cause-effect diagram. The diagram shows how the complex nature of managing the national railway system requires tremendous effort to manage successfully.

\section{Suggested proposals for feasible solutions}

It is necessary to find feasible solutions which can be implemented according to priority, with clear stages and measurable targets to accelerate the restructuring process and prepare for future competition in the national railways industry. We therefore suggest the following proposals for feasible solutions.

\subsection{Strategy to refer back to the original concept of the PSO, IMO, and TAC schemes}

The PSO, IMO, and TAC schemes were originally designed with the intent to unify independent entities. To restore this original intention, the following sequence of stages, as shown in Figure 3, could be implemented: Stage 1) continued use of the current net payment system; Stage 2) a transitional period in which the PSO scheme is separated from the IMO and TAC schemes; and Stage 3) a final 'target' stage in which all the schemes are fully separated from each other. For the government, this policy means that the financial allocation of the PSO scheme takes the form of economy class subsidies, while the IMO scheme becomes compensation for infrastructure maintenance and operation. Meanwhile, train service operators should pay TAC using appropriate collection methods, with its revenue being re-allocated for IMO funded projects. In actual practice, the Stage 2 target was gradually achieved in 2005 by allocating funds amounting to Rp. 270 billion for the PSO scheme (Ministry of Transport, 2005; Ministry of Transport, 2010). Otherwise, the IMO scheme was offset by the TAC scheme because the amounts were equivalent. Therefore, real financial flow only occurred in the PSO scheme.

\subsection{Efforts to provide sufficient financial allocation for rail infrastructure recovery}

Because the IMO scheme was offset with TAC in 2005 and there are no available funds for IMO works, we can assume that to maintain the minimum safety requirements in business operation, PT KA allocated funds from both its commercial passenger and freight revenues and from a small portion of PSO funds (see Figure 4). The normal budget plan of IMO funds in 2005 was around Rp. 600 billion, or a $41 \%$ share of the overall budgets of the PSO, IMO, and TAC schemes. This condition resulted in the worsening of the backlog problem, in which the accumulated backlog reached Rp. 4.6 trillion, or the equivalent of $16 \%$ of the transport sector's fund allocation in the state budget structure of fiscal year 2010 (PT KA, 2007; Ministry of Finance, 2010). In such circumstances, the requirements of sufficient funds for the IMO scheme and the elimination of backlog are extremely important. Based on national fiscal policy and regulations, there are two possible instruments for providing such funds: state budget allocation and foreign loans from international financial institutions. Regarding these instruments, the government's commitment to sustaining political and financial allocation can be considered an initial strategic effort to support these requirements during the restructuring process of the national railway.

\subsection{Improvement of the current TAC concept}

The establishment of appropriate standards to track access charges must be considered carefully, because it will influence both the entry of new market competition participants and the level of competitiveness with other modes of transportation. This should result in the creation of common pricing principles of infrastructure usage. It is generally agreed that a marginal cost pricing policy will result in the most efficient use of the transport infrastructure system (Khisty \& Lall, 1990). Crozet (2004) asserted that the short run marginal cost constitutes the best theoretical solution to the issue of infrastructure charging, although its measurement is complex in practice (Rothengatter, 2003). EMCT (2005) states that the economic principles behind an appropriate infrastructure access regime are well established. Access charges should reflect the marginal cost including external costs, such as the congestion cost, pollution cost, and accident cost, which are caused by each user when they enter the network. This will ensure that the objectives of environmental sustainable development are achieved.

\section{Conclusion}

This paper revealed the development of unsustainable transport policy during the restructuring process of Indonesian Railways. We traced its rational background and development objectives, described its first five years of implementation, the problems that occurred and their impacts on both present service performance as well as preparation for future development.

First, to implement a good transport policy at the practical level, it is difficult to simultaneously achieve all the economic, social, and environmental objectives of sustainable transport development. In most developing countries, the lack of financial allocation due to state budget constraints remains the main factor affecting successful implementation. The case of Indonesian Railways examined in this paper has shown that the funds 
provided by the government were insufficient for the required PSO and IMO payments because of the state budget being shared with other infrastructure sectors. As a result, the net payment system caused improper PSO, IMO, and TAC implementation, which finally resulted in an increasingly complex national railway management system. This experience provides a valuable lesson, that is, in developing countries with various constraints, the development of transport policy should reflect those conditions which best meet demands and allow the supplying of available resources. Therefore, the introduction of new policy instrumentation has its own challenges in terms of properness, effectiveness, and sustainability in improving the current performance system. It should be noted that a wide spectrum of user characteristics (e.g., income level, education level, and social behavior) should be taken into consideration.

Second, in developing countries, political intervention is often involved in the legislation of fiscal policy and sector budget allocation. It is thus not surprising that under such circumstances, the government should have a rational and sound approach in its negotiation process in the parliament and Ministry of Finance. In Indonesia, for example, in 2005, the separation of the target of the PSO scheme from those of the IMO and TAC schemes was successfully achieved by fully allocating funds for the PSO scheme. Accordingly, the next policy objective is the provision of sufficient funds for the IMO scheme while also overcoming the problem of backlog. As long as the objective of full maintenance cannot be achieved, new potential train operators will not be interested in participating in market competition; they need to be assured that the rail infrastructures are well prepared. It also should be noted that a huge amount of capital funds is required to complete such preparation, and once these problems are sufficiently addressed, the government's burden in increasing safety and service performance levels will be eased. This will provide opportunities for moving passengers from other transportation modes, such as cars, buses, and air transport, to trains as their main alternative mode of transportation, which will increase demand as well. Development in this direction aligns well with the aims of sustainable transport development. Therefore, as we have outlined in this paper, focusing on sustained political action as a sustainable approach for allocating sufficient funds to the railway sector plays a critical role in the improvement of the Indonesian Railways restructuring process toward better performance in the future.

\section{References}

Akinyemi, E. O., \& Zuidgeest, M. H. P. (2000). Sustainable development and transportation: past experiences and future challenges, World Transport Policy and Practice, 6, 31-39

Balassa, B. (1990). Indicative planning in developing countries, Journal of Comparative Economics, 14,560 574

Banister, D. (2008). The sustainable mobility paradigm, Transport Policy, 15, 73-80

Campos, J., \& Cantos, P. (2000). Rail transport regulation, Washington DC: World Bank

Crozet, Y. (2004). European railway infrastructure: towards a convergence of infrastructure charging? International Journal of Transport Management, 2, 5-15

Eriksson, L., Garvill, J., \& Nordlund, A.M. (2008). Acceptability of single and combined transport policy measures: the importance of environmental and policy specific beliefs, Transportation Research Part A, 42, 1117-1128

European Conference of Ministers of Transport (ECMT). (2005). Railway reform and charges for the use of infrastructure, Paris: OECD

Everett, S. (2006). Deregulation and reform of rail in Australia: some emerging constraints, Transport Policy, 13, 74-84

Guislain, P. (1997). The privatization challenge: a strategic, legal and institutional analysis of international experience, Washington DC: World Bank

Hatzopoulou, M., \& Miller, E.J. (2009). Transport policy evaluation in metropolitan areas: the role of modelling in decision-making, Transportation Research Part A, 43, 323-338

Ikhsan, M. (2007). Policy reform in Indonesia: agenda and challenges. Paper presented at the first OECD-Southeast Asia Regional Forum: mechanism for policy reform, Jakarta

Khisty, C.J., \& Lall, B.K. (1990). Transportation engineering, New Jersey: Prentice-Hall

Kopicki, R., \& Thompson, L.S. (1995). Best methods of railway restructuring and privatization, Washington DC: World Bank

Link, H. (2004). Rail infrastructure charging and on-track competition in Germany, International Journal of Transport Management, 2, 17-27

Lubis, H.A.S., \& Nurullah, P. (2007). Recent development of Indonesian Railway institution, Journal of Eastern Asia Society for Transportation Studies, 7, 1886-1901

Ministry of Finance. (2010). Main data of state budget 2005-2010, Jakarta: Board of Fiscal Policy 
Ministry of Transport. (1999). Study on evaluation of budget and railway technical standard for supporting PSO, IMO, and TAC schemes, Jakarta: Directorate General of Land Transport

Ministry of Transport. (2000). The contract of implementation on Public Service Obligation (PSO), Infrastructure Maintenance and Operation (IMO), and Track Access Charges (TAC) 2000, Jakarta: Directorate General of Land Transport

Ministry of Transport. (2001). The contract of implementation on Public Service Obligation (PSO), Infrastructure Maintenance and Operation (IMO), and Track Access Charges (TAC) 2001, Jakarta: Directorate General of Land Transport

Ministry of Transport. (2002). The contract of implementation on Public Service Obligation (PSO), Infrastructure Maintenance and Operation (IMO), and Track Access Charges (TAC) 2002, Jakarta: Directorate General of Land Transport

Ministry of Transport. (2003). The contract of implementation on Public Service Obligation (PSO), Infrastructure Maintenance and Operation (IMO), and Track Access Charges (TAC) 2003, Jakarta: Directorate General of Land Transport

Ministry of Transport. (2004). The contract of implementation on Public Service Obligation (PSO), Infrastructure Maintenance and Operation (IMO), and Track Access Charges (TAC) 2004, Jakarta: Directorate General of Land Transport

Ministry of Transport. (2005). The contract of Public Service Obligation for economy class passenger train in 2005, Jakarta: Directorate General of Railway

Ministry of Transport. (2007). The Report of Railways Performance 2002-2006, Jakarta: Directorate General of Railway

Ministry of Transport. (2010). Minister Decree No.7/2010 concerning strategic plan of Ministry of Transport 2010-2014, Jakarta: Secretariat General Ministry of Transport

Mizutani, F. \& Shoji. K., (2004). Rail operation - infrastructure separation: the case of Kobe rapid transit railway, Journal of Transport Policy, 11, 251-263

Muthohar, I., \& Sutomo, H. (2003). Privatisation model of Indonesian Railways, case study: railways in Java Island. Paper presented at the Inter University Forum on Transport Studies VI, Makassar

Muthohar, I., Sumi, T., \& Sutomo, H. (2009). The implementation and impacts of PSO, IMO and TAC schemes on national railway reform in Indonesia. Paper presented at Eastern Asia Society for Transportation Studies Conference, Surabaya

PT Kereta Api. (2007). The study on backlog problem in infrastructure and rolling stock maintenance, Bandung: PT KA

Rothengatter, W. (2003). How good is first best? marginal cost and other pricing principles for user charging in transport, Transport Policy, 10, 121-130

Saadatian, O., Tahir, O.M., \& Dola, K. (2010). Identifying challenges in implementing sustainable practices in a developing nation, Journal of Sustainable Development, 3, 107 - 116

Satriya, E. (2007). Connecting the infrastructure discrepancy by PSO scheme, Jakarta: Coordinating Ministry of Economic Affairs

State Secretary Minister. (1999). The Joint Decree of 3 Ministers of Minister of Transport, Minister of Financial, and State Minister of National Development Planning Agency concerning Public Service Obligation (PSO), Infrastructure Maintenance and Operation (IMO), and Track Access Charges (TAC), Jakarta

United Nations Economic and Social Commission for Asia and the Pacific (UN-ESCAP) and Asia Institute of Transport Development (AITD). (2000). Sustainable Transport Pricing and Charges: Principles and Issues. [Online] Available: http://unescap.org/ttdw/Publications/TPTS_pubs/pricing_fulltext.pdf ( February 28th, 2010)

Vieira, J., Moura, F., \& Viegas, J.M. (2007). Transport policy and environmental impacts: the importance of multi-instrumentality in policy integration, Transport Policy, 14, 421-432

Wu, J.H., \& Nash, C. (2000). Railway reform in China, Transport Reviews, 20, pp. 25-48 
Table 1. Amounts of PSO, IMO, TAC schemes in 2000-2004 (in billions of Rp.).

\begin{tabular}{cccccc}
\hline & & PSO & IMO & TAC & $\begin{array}{c}\text { NET }= \\
\text { PSO+IMO-TAC }\end{array}$ \\
\hline \multirow{2}{*}{2000} & Proposed & 434.50 & 399.25 & 592.15 & 241.60 \\
& Determined & 255.31 & 316.22 & 512.34 & 59.18 \\
& Realized & 596.11 & 354.31 & 547.22 & 403.21 \\
\hline \multirow{2}{*}{2001} & Proposed & 342.28 & 489.14 & 684.37 & 147.05 \\
& Determined & 256.71 & 410.88 & 607.59 & 60.00 \\
& Realized & 529.50 & 421.10 & 607.59 & 343.01 \\
\hline \multirow{2}{*}{2002} & Proposed & 326.87 & 589.32 & 693.37 & 222.83 \\
& Determined & 224.96 & 528.41 & 693.37 & 60.00 \\
& Realized & 495.99 & 512.37 & 693.37 & 314.99 \\
\hline \multirow{2}{*}{2003} & Proposed & 217.31 & 590.73 & 558.68 & 249.36 \\
& Determined & 148.20 & 566.68 & 608.69 & 106.20 \\
& Realized & 419.68 & 546.61 & 608.69 & 357.61 \\
\hline \multirow{2}{*}{2004} & Proposed & 193.66 & 755.11 & 659.19 & 289.58 \\
& Determined & 93.07 & 569.55 & 522.62 & 140.00 \\
& Realized & 388.09 & 538.25 & 522.62 & 403.72 \\
\hline
\end{tabular}

Source: Ministry of Transport (2000, 2001, 2002, 2003, 2004).

Table 2. Yearly accident rates.

\begin{tabular}{lccccc}
\hline & 2002 & 2003 & 2004 & 2005 & 2006 \\
\hline Type of accident & & & & & \\
- Collision between trains & 6 & 7 & 7 & 9 & 5 \\
- Collision between train and vehicle & 58 & 57 & 31 & 10 & 22 \\
- Derailment & 69 & 80 & 90 & 99 & 52 \\
- Natural disaster & 12 & 7 & 4 & 3 & 7 \\
Number of victims (persons) & & & & & \\
- Fatal injuries & 74 & 72 & 78 & 36 & 50 \\
- Serious injuries & 114 & 104 & 87 & 85 & 71 \\
- Minor injuries & 60 & 122 & 33 & 111 & 52 \\
Number crossings & & & & & \\
- Formal and guarded & 1145 & 1145 & 1145 & 1145 & 1145 \\
- Formal and unguarded & 6907 & 6956 & 6981 & 6926 & 6936 \\
- Informal & 403 & 403 & 486 & 314 & 314 \\
\hline
\end{tabular}

Source: Ministry of Transport (2007).

Table 3. Yearly service characteristics.

\begin{tabular}{lccccc}
\hline & 2002 & 2003 & 2004 & 2005 & 2006 \\
\hline On-time passenger train departures (\%) & 72 & 80 & 81 & 70 & 82 \\
On-time freight train departures (\%) & 29 & 24 & 21 & 23 & 25 \\
On-time passenger train arrivals (\%) & 22 & 19 & 21 & 22 & 23 \\
On-time freight train arrivals (\%) & 30 & 24 & 22 & 19 & 19 \\
Number of signal disruptions & 2574 & 3354 & 1650 & 1600 & 1550 \\
Number of locomotive failures & 2038 & 1719 & 1552 & 1519 & 1724 \\
Running speed on track (\% of total length) & & & & & \\
- $100-120 \mathrm{~km} /$ hour & 3.2 & 3.6 & 4.0 & 8.6 & 9.1 \\
- $80-99 \mathrm{~km} /$ hour & 34.9 & 35.7 & 37.1 & 39.9 & 42.2 \\
- $60-79 \mathrm{~km} /$ hour & 21.8 & 23.0 & 23.3 & 23.7 & 24.6 \\
- $<60 \mathrm{~km} /$ hour & 40.2 & 37.6 & 35.6 & 27.9 & 24.1 \\
\hline
\end{tabular}

Source: Ministry of Transport (2007). 


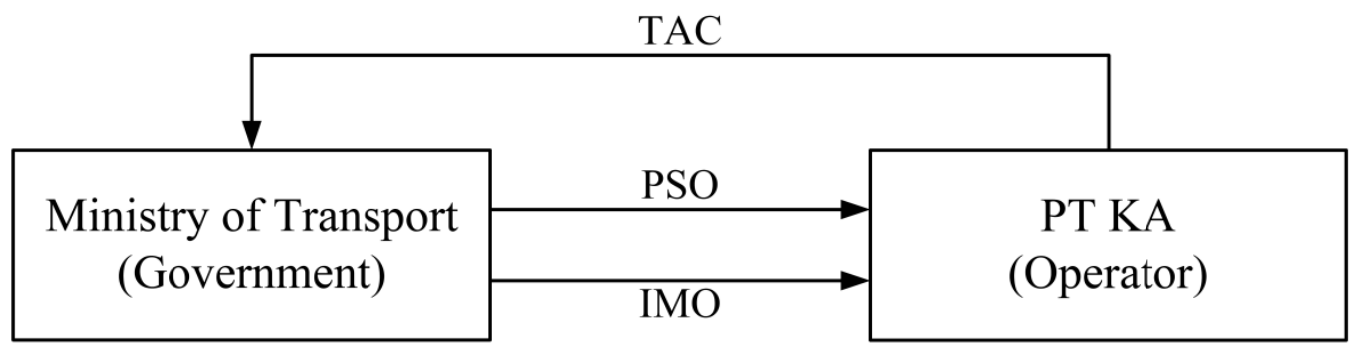

Source: Muthohar et al. (2009).

Figure 1. Role of government and operator in railway budget mechanism.

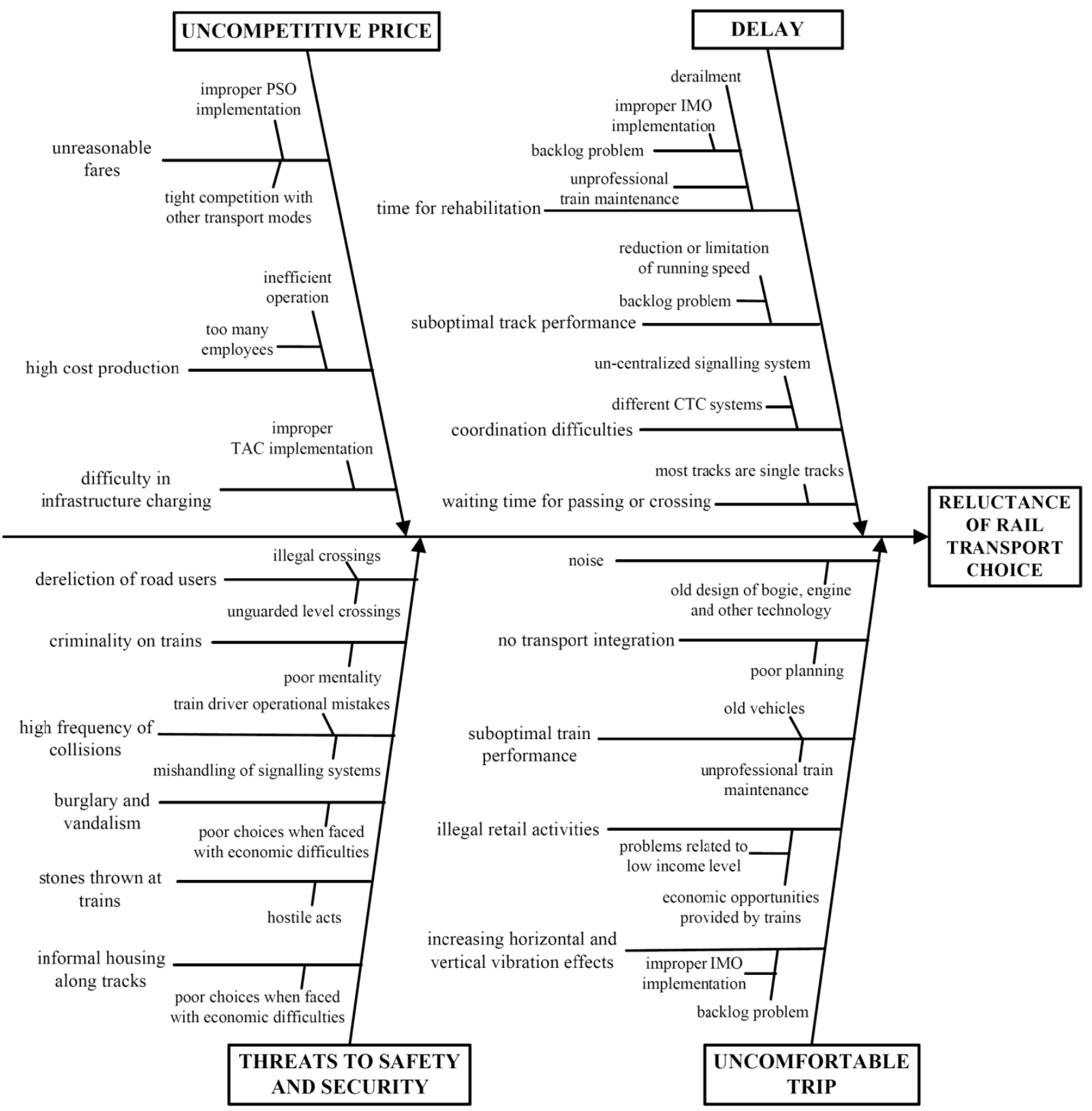

Figure 2. Cause-effect relationships of national railway performance. 


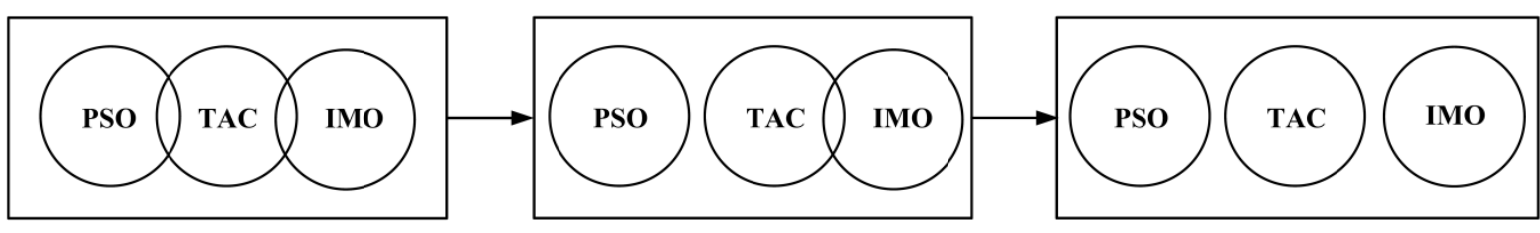

stage 1

stage 2

stage 3

Source: Muthohar et al. (2009).

Figure 3. Sequence of stages toward the original concepts of the PSO, IMO, and TAC schemes.

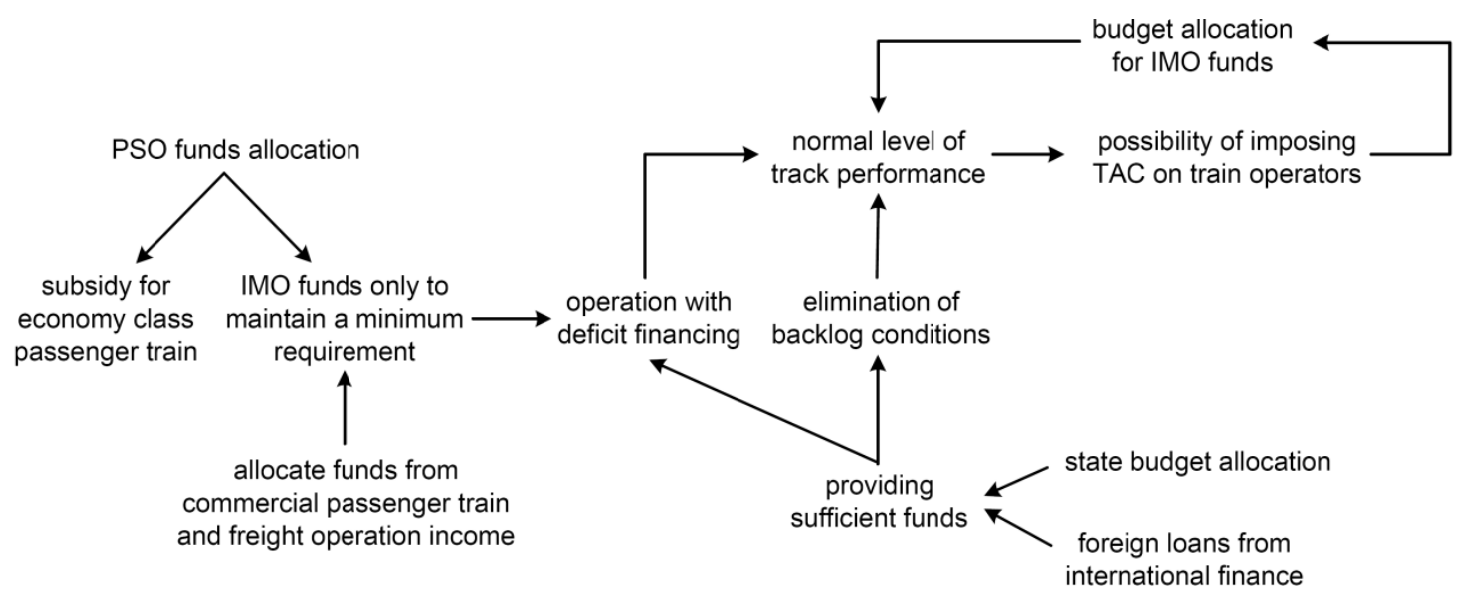

Figure 4. Process toward normal track performance conditions. 